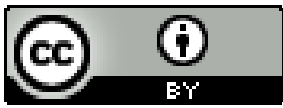

\title{
RECONHECIMENTO VALORATIVO DO PATRIMÔNIO QUILOMBOLA POR MEIO DO MAPEAMENTO PARTICIPATIVO
}

\author{
Eduardo Rodrigues Alves ${ }^{1}$
}

\begin{abstract}
Resumo: O processo de salvaguarda dos territórios quilombolas atualmente dispõe de problemáticas que desafiam sua visibilidade enquanto patrimônios culturais. Diante deste contexto, busca-se compreender o processo de valorização patrimonial dos territórios quilombolas por intermédio da cartografia participativa, sob a perspectiva da geoeducação. A partir da aproximação com a Comunidade de Conceição dos Caetanos, em Tururu-CE, foi possível estabelecer práticas de educação patrimonial e de mapeamento participativo capazes de fundamentar uma análise acerca da relevância desses processos para o autoreconhecimento das comunidades quilombolas. Tal reconhecimento se deu a partir do levantamento de elementos que compõem o patrimônio cultural da Comunidade e da própria percepção do território como um patrimônio cultural em si. Com isso, percebe-se a importância de viabilizar por meio do olhar geográfico e cartográfico estratégias de percepção e valorização das comunidades quilombolas, diante das problemáticas e potencialidades existentes nestes territórios.
\end{abstract}

Palavras-Chave: Geoeducação; Território; Patrimônio Cultural; Comunidades Remanescentes de Quilombo.

\section{VALUABLE RECOGNITION OF QUILOMBOLA HERITAGE THROUGH PARTICIPATORY MAPPING}

Abstract: The process of safeguarding quilombola territories currently has problems that challenge their visibility as cultural heritage. In this context, we seek to understand the process of heritage appreciation of quilombola territories through participatory cartography, from the perspective of geoeducation. From the approach to the Conceição dos Caetanos Community, in Tururu-CE, it was possible to establish practices of heritage education and participatory mapping capable of supporting an analysis about the relevance of these processes for the self-recognition of quilombola communities. This recognition was based on the survey of elements that make up the cultural heritage of the Community and the perception of the territory as a cultural heritage in itself. With this, one realizes the importance of making viable through the geographic and cartographic look strategies of perception and valorization of quilombola communities, in face of the problems and potentialities existing in these territories.

${ }^{1}$ Mestrando em Geografia pela Universidade Federal do Ceará. ociberdudu@gmail.com

Revista da ABPN • v. 12, n. Ed. Especial - Caderno Temático: "Geografias Negras" • abril de 2020, p. 153-174 
Key-words: Geoeducation; Territory; Cultural Heritage; Quilombo Remaining Communities.

\section{RECONOCIMIENTO VALIOSO DEL PATRIMONIO DE QUILOMBOLA A TRAVÉS DEL MAPEO PARTICIPATIVO}

Resumen: El proceso de salvaguardar los territorios de quilombolas actualmente tiene problemas que desafían su visibilidad como patrimonio cultural. En este contexto, buscamos comprender el proceso de apreciación del patrimonio de los territorios quilombolas a través de la cartografía participativa, desde la perspectiva de la geoeducación. Del contacto con la Comunidad Conceição dos Caetanos, en Tururu-CE, fue posible establecer prácticas de educación patrimonial y mapeo participativo capaces de apoyar un análisis sobre la relevancia de estos procesos para el auto reconocimiento de las comunidades quilombolas. Dicho reconocimiento tuvo lugar a partir de la encuesta de elementos que conforman el patrimonio cultural de la Comunidad y la percepción del territorio como patrimonio cultural en sí mismo. Con esto, se destaca la importancia de hacer viable a través de las estrategias de percepción geográfica y cartográfica de percepción y valorización de las comunidades quilombolas, frente a los problemas y potencialidades existentes en estos territorios.

Palabras-clave: Geoeducación; Territorio; Patrimonio Cultural; Comunidades remanentes de Quilombo.

\section{RECONNAISSANCE VALABLE DU PATRIMOINE DE QUILOMBOLA À TRAVERS UNE CARTOGRAPHIE PARTICIPATIVE}

Résumé: Le processus de sauvegarde des territoires de quilombola connaît actuellement des problèmes qui remettent en cause leur visibilité en tant que patrimoine culturel. Dans ce contexte, nous cherchons à comprendre le processus d'appréciation patrimoniale des territoires de quilombola à travers la cartographie participative, dans la perspective de la géoéducation. De l'approche à la communauté de Conceição dos Caetanos, à Tururu-CE, il a été possible d'établir des pratiques d'éducation au patrimoine et de cartographie participative capables de soutenir une analyse de la pertinence de ces processus pour l'auto-reconnaissance des communautés de quilombola. Cette reconnaissance se fonde sur une enquête sur les éléments constitutifs du patrimoine culturel de la Communauté et sur la perception du territoire comme patrimoine culturel en soi. Avec cela, on se rend compte de l'importance de rendre viable à travers les stratégies d'aspect géographique et cartographique de la perception et de la valorisation des communautés de quilomboles, devant aux problèmes et potentialités existant dans ces territoires.

Mots-clés: Géoéducation; Territoire; Patrimoine culturel; Communautés Quilombo restantes.

Revista da ABPN • v. 12, n. Ed. Especial - Caderno Temático: “Geografias Negras” • abril de 2020, p. 153-174 


\section{INTRODUÇÃO}

Os quilombos, nascidos da resistência à escravidão e da busca pela liberdade, foram, ao longo do tempo, perdendo esse objetivo inicial. Atualmente são redutos de uma cultura preservada, os quais denominamos de "comunidades quilombolas" ou "remanescentes de quilombos". (BERUTTI; LISBOA; SANTOS, 2012, p. 33).

Muito além de um reduto de preservação cultural, as comunidades quilombolas atualmente representam grupos de uma cultura viva e pulsante. Uma cultura com longas raízes fincadas, mas não estacionária. E diante desta relevância, é preciso discutir aspectos relativos ao reconhecimento valorativo destes territórios culturais.

Apesar do relativo avanço na identificação e reconhecimento oficial das Comunidades Remanescentes de Quilombo (CRQs) - sobretudo pelas articulações entre movimentos sociais e da Fundação Cultural Palmares - este avanço não supre a necessidade de um reconhecimento valorativo das comunidades quilombolas como patrimônios culturais que são. Diversas demandas, como a titulação de suas terras, o acesso a moradia digna, saneamento básico, saúde e educação adequada ao contexto quilombola, representam problemas que precisam ser resolvidos para o seu devido reconhecimento histórico-cultural. E no âmbito destas questões, é fundamental que o Estado estabeleça articulações e perceba a importância deste patrimônio vivo brasileiro.

Todavia, o processo de reconhecimento valorativo de comunidades quilombolas perpassa - antes de qualquer articulação entre diferentes instâncias - pela sua autopercepção como território-patrimônio, que por sua vez resgata territorialidades construídas ao longo do tempo no espaço geográfico para compreender as formas do presente e as traçar projeções para a permanência e reconstrução futura destes territórios. E este é o ponto de partida para a reivindicação desta percepção no âmbito externo às comunidades, tanto pela esfera civil quanto pela esfera do poder público.

O presente texto levanta uma discussão em torno deste processo de autoconhecimento patrimonial a partir de atividades desenvolvidas junto a comunidade quilombola de Conceição dos Caetanos, no município de Tururu, Ceará.

Com a problemática destacada anteriormente, os questionamentos iniciais que impulsionaram tal discussão foram: de que forma esta identidade é percebida e construída

Revista da ABPN • v. 12, n. Ed. Especial - Caderno Temático: "Geografias Negras" • abril de 2020, p. 153-174 
internamente pela Comunidade? E quais mecanismos geoeducativos podem ser utilizados para a interpretação espacial destas questões e a percepção deste patrimônio quilombola? Assim, este artigo objetiva compreender o processo de valorização patrimonial em territórios quilombolas a partir do mapeamento participativo, sob a ótica da geoeducação.

São questões que embora não se disponham para um contexto espacial específico, foram percebidas em torno de um estudo contextualizado. Nesse sentido, para o correto entendimento desta representatividade de Conceição dos Caetanos, no âmbito de sua municipalidade, é importante fazer uma breve caracterização do município de Tururu, para em seguida dirigir atenção propriamente para as questões relativas à Comunidade no contexto em que se insere.

Tururu se estende por 202,3 km², localiza-se a $111 \mathrm{~km}$ da cidade de Fortaleza, e estima-se que em 2018 contava com uma população de 16.105 habitantes (BRASIL, 2018b). Seu território é composto majoritariamente por zona rural, com pequenas manchas urbanas dentro de seus quatro distritos: Tururu (sede), São Pedro do Gavião, Conceição e Cemoaba. Em termos de domínios naturais, o território do município dispõe sobretudo de sertões, com uma pequena parcela a sudoeste marcada por serras úmidas (CEARÁ, 2007).

O Rio Mundaú acompanha o limite oeste deste município e também margeia Conceição dos Caetanos. Ainda utilizado como fonte de água para as atividades domésticas de muitas famílias, o Rio até hoje também representa um ambiente de lazer para as famílias. Integra, portanto, um dos elementos da paisagem característica do local, que juntamente com outros elementos materiais e imateriais (que serão abordados mais adiante) compõem o quadro de referência patrimonial da Comunidade.

Neste sentido, para a devida constatação deste quadro patrimonial comunitário é preciso apontar para a importância do olhar geográfico, neste caso potencializado pela cartografia participativa. O conjunto de práticas desenvolvidas com a Comunidade pode ser seccionado em duas partes para melhor aproveitamento da discussão. A primeira delas trata-se de uma fase de reconhecimento-aproximação entre pesquisador e comunidade, um processo de troca de conhecimentos que englobou: entrevistas semiestruturadas, intervenções em sala de aula e um trabalho de campo com estudantes perpassando por pontos específicos da Comunidade. 
A segunda metade do processo, mais conclusiva e sintetizadora dos conhecimentos construídos, foi auxiliada pela cartografia participativa com a construção de um mapeamento patrimonial da Comunidade. Os aspectos metodológicos mais relevantes e as apreensões feitas durante e após a realização das etapas embasam a análise proposta anteriormente.

Entretanto, antes de adentrar no campo da descrição das etapas, é preciso apontar a fundamentação teórica utilizada para a construção metodológica proposta. O tópico seguinte dispõe deste levantamento conceitual (em se tratando da triangulação entre território, patrimônio cultural e comunidades quilombolas) e metodológico (em se tratando das atividades geoeducativas, incluindo o mapeamento participativo).

\section{FUNDAMENTOS TEÓRICO-METODOLÓGICOS}

O conceito de patrimônio cultural, na ciência geográfica, pode ser entendido como uma referência cultural dos grupos humanos e que por meio das categorias de análise da Geografia adquire expressão espacial, representando um dos caminhos na análise da dimensão geográfica da cultura (FIGUEIREDO, 2013).

No âmbito das comunidades quilombolas, muito marcadas pelo aspecto culturalhistórico de seus territórios, o conceito de patrimônio cultural é fundamental para seu autoreconhecimento. E para bem compreender a relação entre o patrimônio cultural e a espacialidade dos grupos humanos, é fundamental entender a relação entre território e o patrimônio cultural das CRQs.

Traçando uma breve síntese em torno do conceito, a partir de Haesbaert (2007; 2008), entende-se que o território esteve por muito tempo vinculado à ideia de terraterritorium, com dominação jurídica/política do espaço e também esteve associado ao entendimento de terreoterritor, com imposição de força e medo para o deter seu controle (HAESBAERT, 2008, p. 19). Entretanto, atualmente o território passa a ser entendido também pelo viés cultural, passando a destacar sentidos de apropriação simbólica do espaço.

Em Haesbaert (2007), existem três diferentes dimensões em torno do território: econômica, política e cultural. A perspectiva econômica de território interpreta-o como recurso econômico, vislumbrando uma rede de territórios com funções econômicas 
diferenciadas no espaço geográfico. A perspectiva política de território se refere mais incisivamente à relação espaço-poder, mas um poder que não é obrigatoriamente exercido pelo Estado, e sim por uma gama de atores e agentes que atuam no espaço geográfico. Já a perspectiva cultural ou simbólico-cultural, interpreta o território como resultado da apropriação simbólica que grupos humanos de pessoas faz de um espaço.

Pode-se estabelecer uma aproximação entre a expressão de territorialidade das comunidades quilombolas por estas três diferentes perspectivas do território, entretanto, é pela perspectiva simbólico-cultural que se compreende a apropriação simbólica do território, composta por referências histórico-culturais, que caracteriza a territorialidade das comunidades quilombolas. De modo que esta terceira perspectiva ganha maior peso na proposta deste trabalho, uma vez que enfatiza a relação humana com o espaço por meio da associação simbólica-cultural, produzindo territorialidades, relações entre território e identidade (HAESBAERT, 2007).

Esta relação sócio territorial representa um processo fundamental para a construção de uma identidade em torno dos elementos culturais do patrimônio quilombola. Cunha Junior (2012), entende que a identidade se associa com a territorialidade constituindo um conjunto de referência cultural para aquilo que vem a ser denominado como patrimônio cultural.

Identidade e territorialidade são dois requisitos fundamentais para a definição de referência cultural e esta, por sua vez, para os conceitos ampliados do que vem a ser os patrimônios culturais materiais e imateriais. A referência cultural tem forte vinculação com a relação de pertencimento da "nossa identidade" e com a "nossa territorialidade" (CUNHA JUNIOR, 2012, p. 163).

Assim, o conceito de comunidade quilombola, ou comunidade remanescente de quilombo, se insere no âmbito dos patrimônios culturais (que podem ser materiais e imateriais) produtores de identidades e de territorialidades. É preciso perceber que as comunidades possuem e ao mesmo tempo são patrimônio cultural, uma vez que possuem elementos em sua paisagem e em sua formação histórica que as diferenciam umas das outras; e que são, antes de mais nada, patrimônios da história e da cultura brasileira.

Com este entendimento em perspectiva, para os exercícios educativos de educação patrimonial e de mapeamento participativo foram essenciais algumas referências básicas sobre: a formação e a ação educadora de professores de Geografia 
(CALLAI, 2013; FREIRE, 2001; PIMENTA; LIMA, 2006); sobre a importância da Geografia para a compreensão de mundo e suas dinâmicas e da temática da pluralidade cultural para o ensino de Geografia (ANJOS, 2006); e sobre questões étnico-raciais no ensino (BRASIL, 2003; RATTS, 2010), incluindo o desenvolvimento de experiências e reflexões sobre uma educação antirracista e de projetos com vistas a reafirmação do lugar do povo negro na sociedade brasileira (SANTOMÉ, 1995).

Em torno das comunidades quilombolas, a partir destes autores é possível entender que a Geografia é de grande importância pois, assume "grande importância dentro da temática da pluralidade cultural no processo de ensino" (ANJOS, 2006, p. 199). Neste sentido, uma educação quilombola se torna uma modalidade de educação bastante beneficiada na incorporação dos conhecimentos geográficos. Porém, podemos perceber a falta de apreço que a educação quilombola recebe quando Santomé (1995) destaca a carência de experiências e reflexões sobre uma educação antirracista e de programas plurilinguísticos, que são de grande importância para reafirmar a posição das comunidades negras na sociedade.

A Educação Patrimonial (EP), por sua vez, é aqui percebida como conjunto de processos educativos formais e não formais com enfoque no Patrimônio Cultural, que é apropriado socialmente como recurso para a compreensão sócio histórica das referências culturais em todas as suas manifestações (IPHAN, 2014). Para uma melhor compreensão sobre a EP, também foram norteadoras as contribuições de Oliveira, Lima e Carneiro (2013) acerca da Educação Patrimonial assentada em patrimônios culturais e sua percepção (defasada) no campo da Geografia Escolar.

E para o desenvolvimento das atividades de mapeamento dos elementos patrimoniais culturais da Comunidade, além dos autores que versam sobre as práticas educativas envolvendo a Geografia e o patrimônio cultural, foram fundamentais os autores que tratam sobre as diferentes possibilidades de aplicação do mapeamento participativo (SILVA; VERBICARO, 2006; ANDRADE; CARNEIRO, 2009).

Gisele Girardi (2016), entende o mapeamento participativo como uma atividade potencialmente positiva e emancipatória para as comunidades. E entende que "o objetivo último das práticas de cartografia social ou participativa é promover a visibilidade de territorialidades" (GIRARDI, 2016, p. 88). Esta construção coletiva possibilita uma 
reflexão coletiva sobre o cotidiano, o exercício de atitudes cidadãs e a até a melhoria da qualidade de vida da população (GORAYEB, MEIRELES E SILVA, 2015).

Girardi (2016) afirma ainda que,

Não há uma metodologia fixa para a realização do trabalho, mas diretrizes gerais que envolvem a realização de oficinas, a capacitação da comunidade para o uso de recursos e técnicas cartográficas, a produção dos mapas e dos fascículos pela equipe técnica a partir do material produzido pelas comunidades nas oficinas, a validação do resultado pela comunidade e a publicação do fascículo (GIRARDI, 2016, p.87).

Outro importante entendimento sobre a temática se dá com Gorayeb, Meireles e Silva (2015), que entendem que os mapas participativos são construídos:

a partir do envolvimento de vários atores, e não só de apenas um indivíduo ou grupo. Este tipo de mapa tem a característica de aproveitar ao máximo da realidade geográfica, aliás, das realidades vividas em um determinado espaço, diminuindo uma das características do mapa: ele revela a visão do autor. Então, se o mapa é considerado como a abstração do mundo e é sempre elaborado a partir de um ponto de vista, quando se constrói mapas com várias mãos, aumentase a probabilidade de aproximação da realidade do mundo (GORAYEB; MEIRELES; SILVA, 2015, p. 18).

Assim, compreende-se o mapeamento participativo e as práticas de Educação Patrimonial como uma união capaz de desenvolver o ensino e a aprendizagem em Geografia inserindo a comunidade dentro da prática educativa com crianças, jovens, adultos e idosos.

A partir dos conceitos apresentados, o diálogo conceitual volta-se para o conceito de geoeducação, que neste estudo é capaz de incorporar os conceitos anteriormente citados. Para a incorporação do termo no estudo, serviram como base as reflexões construídas por Oliveira $(2014 ; 2015)$, que entende a geoeducação como:

exercício de envolvimento de uma coletividade, com seu espaço coletivo peculiar (simbólico), visando efetivo aperfeiçoamento da aprendizagem valorativa. Por extensão, tal aperfeiçoamento demanda o equivalente exercício de interpretação espacial do processo educativo. Portanto, a geoeducação é ao mesmo tempo uma prática e um saber contextualizado na ritualização do estar na Terra (OLIVEIRA, 2015, p.34).

Ampliando este entendimento, a geoeducação enquanto prática demanda uma série de atividades, formais ou informais, capazes de acolher o potencial educativo 
presente na territorialidade e a cultura, neste caso, das CRQs. E nesse sentido, é fundamental o engajamento com uma Educação Patrimonial que se permita emergir a partir da interação com os diferentes valores patrimoniais, se opondo a uma conscientização cega da necessidade de proteção daquilo registrado institucionalmente como "patrimonial" (OLIVEIRA, 2014). Já enquanto saber contextualizado, a geoeducação potencializa a análise dos aspectos culturais do território quilombola, que representa um terreno fértil para o aperfeiçoamento geoeducacional. E por meio deste jogo de relações entre os conceitos, as CRQs representam um patrimônio geoeducacional a ser reconhecido e valorizado.

Diante desta malha conceitual, passamos para a disposição das atividades realizadas junto à comunidade de Conceição dos Caetanos.

\section{DESENVOLVIMENTO}

Na condição de pesquisador-licenciando e descendente de moradores de Tururu, a aproximação inicial com a Comunidade se deu a partir de contatos prévios e trabalhos de campo consecutivos, quando foram realizadas entrevistas semiestruturadas com lideranças comunitárias a fim de compreender a formação da comunidade e seus avanços, desafios, suas problemáticas e potencialidades. Os trabalhos de campo também se pautaram no reconhecimento do cotidiano das comunidades, a dinâmica de alguns de seus espaços mais simbolicamente representativos, além do acompanhamento da tradicional Festa do Zumbi, realizada anualmente em comemoração ao dia da Consciência Negra, no dia 20 de dezembro.

Para o desenvolvimento desta discussão, entretanto, o enfoque se dará em torno dos desafios e potencialidades em torno da Comunidade e sua percepção patrimonial, sobretudo no campo da educação mediada pelo conhecimento geográfico.

\subsection{Percepção da comunidade como espaço educativo}

A partir da aproximação com a Escola Caetano José da Costa em 2017, percebemos que o déficit de abordagens significativas e metodologias adequadas ao ensino de Geografia em Conceição dos Caetanos prejudica a aprendizagem geográfíca dentro - e consequentemente fora - do espaço escolar. Uma vez que os estudantes perdem

Revista da ABPN • v. 12, n. Ed. Especial - Caderno Temático: “Geografias Negras” • abril de 2020, p. 153-174 
o interesse e a curiosidade sobre a disciplina, perde-se a possibilidade de fortalecer o debate sobre o povo negro e sua cultura no dia-a-dia.

A partir das observações e de conversas com professores e gestores da Escola, desenvolvemos uma atividade que interagiu os conteúdos da Geografia com o contexto vivido pelos estudantes.

A intervenção inicial foi realizada com uma turma de $8^{\circ}$ ano do Ensino Fundamental, com a parceria de sua professora de Geografia e de Sandra Caetano, moradora da Comunidade e então professora do Projeto Novo Mais Educação. Dividida em duas etapas, a atividade objetivou exercitar conhecimentos geográficos em torno do contexto comunitário, enfatizando a seus elementos afroculturais; e foi proposta como uma possibilidade da Escola se apropriar destes conhecimentos geográficos com uma melhor interação escola-comunidade.

$\mathrm{Na}$ primeira etapa da intervenção, iniciamos uma aula de geografia com a exibição do curta-metragem ("Dos Grilhões ao Quilombo" - quarto episódio da série "500 anos: o Brasil Colônia na TV”, produzido pela TV Escola). Após a exibição do curta, os estudantes socializaram o que lhes chamou atenção no filme. A partir da listagem, avançamos o nosso diálogo sobre o olhar geográfico, visto que o curta-documentário aborda um contexto geral sobre o início da formação dos quilombos no Brasil, e o nosso enfoque se voltou para o contexto local, com a constituição e caracterização de Conceição dos Caetanos. Para melhor guiar o processo dialógico, elaboramos um quadro com tópicos importantes.

Em suma, o intuito desta etapa primeira em específico foi de promover um aprendizado sobre os quilombos no Brasil relacionando o contexto do filme com o contexto local; além de evidenciar a Geografia presente no filme e como esta disciplina contribui para compreender a realidade.

Os estudantes também produziram mapas mentais da Comunidade com os locais mais representativos e afetivos para cada um. Esta atividade teve o intuito de que o estudante pudesse representar os locais na Comunidade que são considerados mais representativos da mesma, locais que fizeram parte da sua história e da sua vivência. Outro objetivo também foi o de filtrar locais na Comunidade mais marcantes para os estudantes, e se são locais fortalecem o auto reconhecimento como quilombola e o sentimento de pertencimento para com a Comunidade. 
Também utilizamos de maneira complementar o software Google Earth em um projetor digital e foram exibidas imagens de satélite da Comunidade, e dialogamos sobre a relevância pessoal e coletiva dos locais que foram desenhados.

Toda esta primeira etapa serviu como base para a segunda etapa, que consistiu em uma aula de campo, com um percurso em caminhada, com diálogos curtos em pontos marcantes da Comunidade elencados pela turma.

A partir dos pontos elencados pela turma de estudantes no primeiro momento da intervenção, iniciamos o trajeto do trabalho de campo em frente à EMEF Caetano José da Costa, na Praça (e centro) da Comunidade (Figura 1), que engloba estabelecimentos comerciais, a Igreja de N. Sra ${ }^{\mathrm{a}}$. das Graças e casas antigas, onde pudemos falar de sua centralidade e sua importância para o ordenamento das casas em seu entorno, um padrão visto em muitas cidades interioranas do Ceará. Falamos também da influência do cristianismo dentro da Comunidade e sobre religiões de matriz africana no Brasil.

Figura 1: Diálogo na Praça da Igreja de Nossa Senhora das Graças realizado no trabalho de campo em Conceição dos Caetanos.

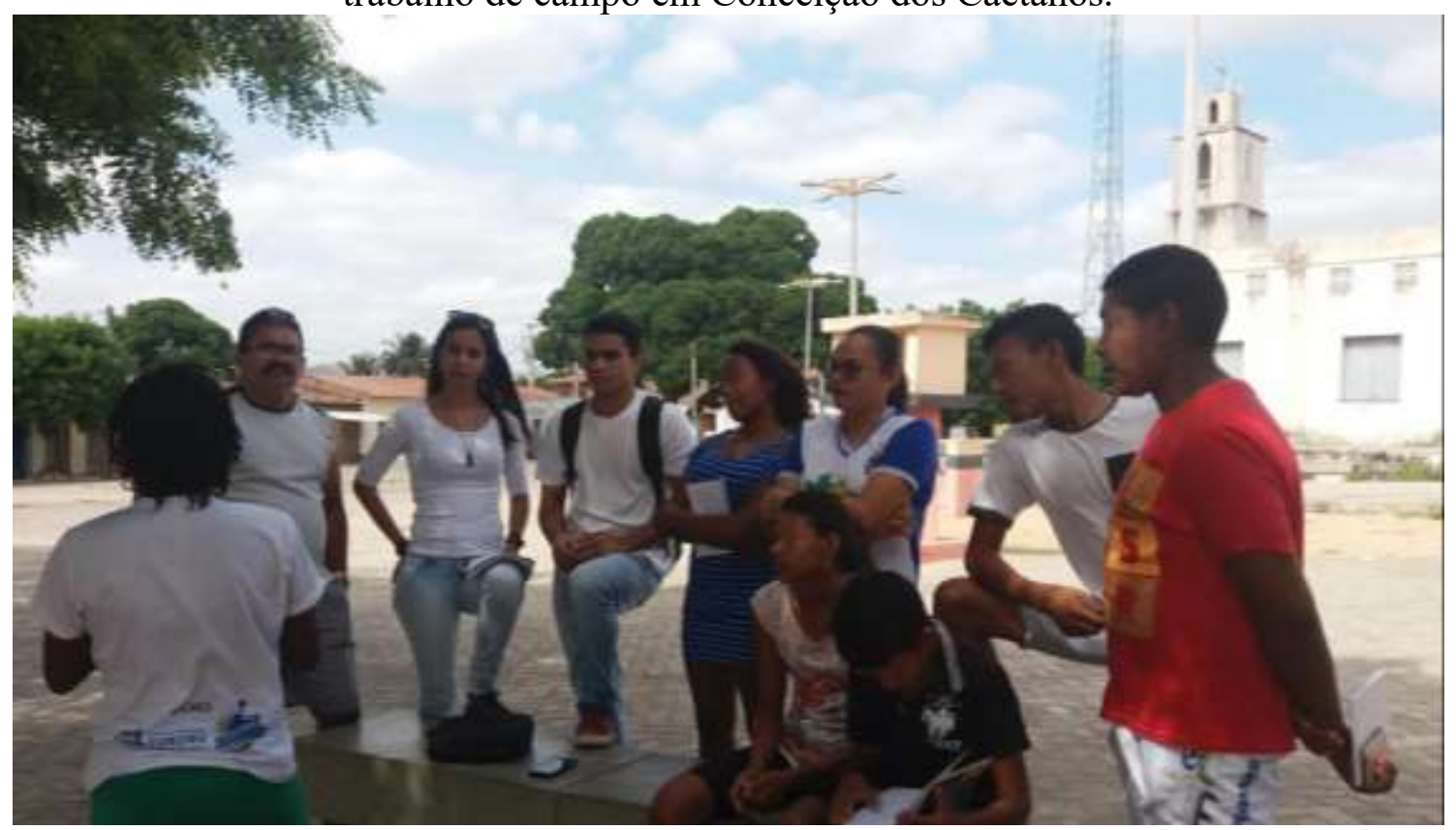

Fonte: Acervo do autor, 2020.

Em seguida conversamos próximo a uma casa de farinha, com uma área de cultivo de mandioca ao fundo, abordando os aspectos econômicos inerentes a Comunidade em sua relação de contribuição para o Município. Pudemos também falar sobre outras formas de renda além da agricultura na Comunidade. 
A terceira parada se deu em um ponto de embarque/desembarque de passageiros, que fica em um dos acessos à Comunidade (Figura 2). Dialogamos sobre os fluxos diversos que ocorrem na comunidade, sobre a relação destes fluxos com os fixos (SANTOS, 1965) que envolvem a comunidade, sua relação com os distritos próximos e com municípios vizinhos. Neste local, também foi possível observar bem a paisagem semiárida que marca o entorno da Comunidade.

Figura 2: Diálogo no ponto de embarque e desembarque de passageiros realizado no trabalho de campo em Conceição dos Caetanos.

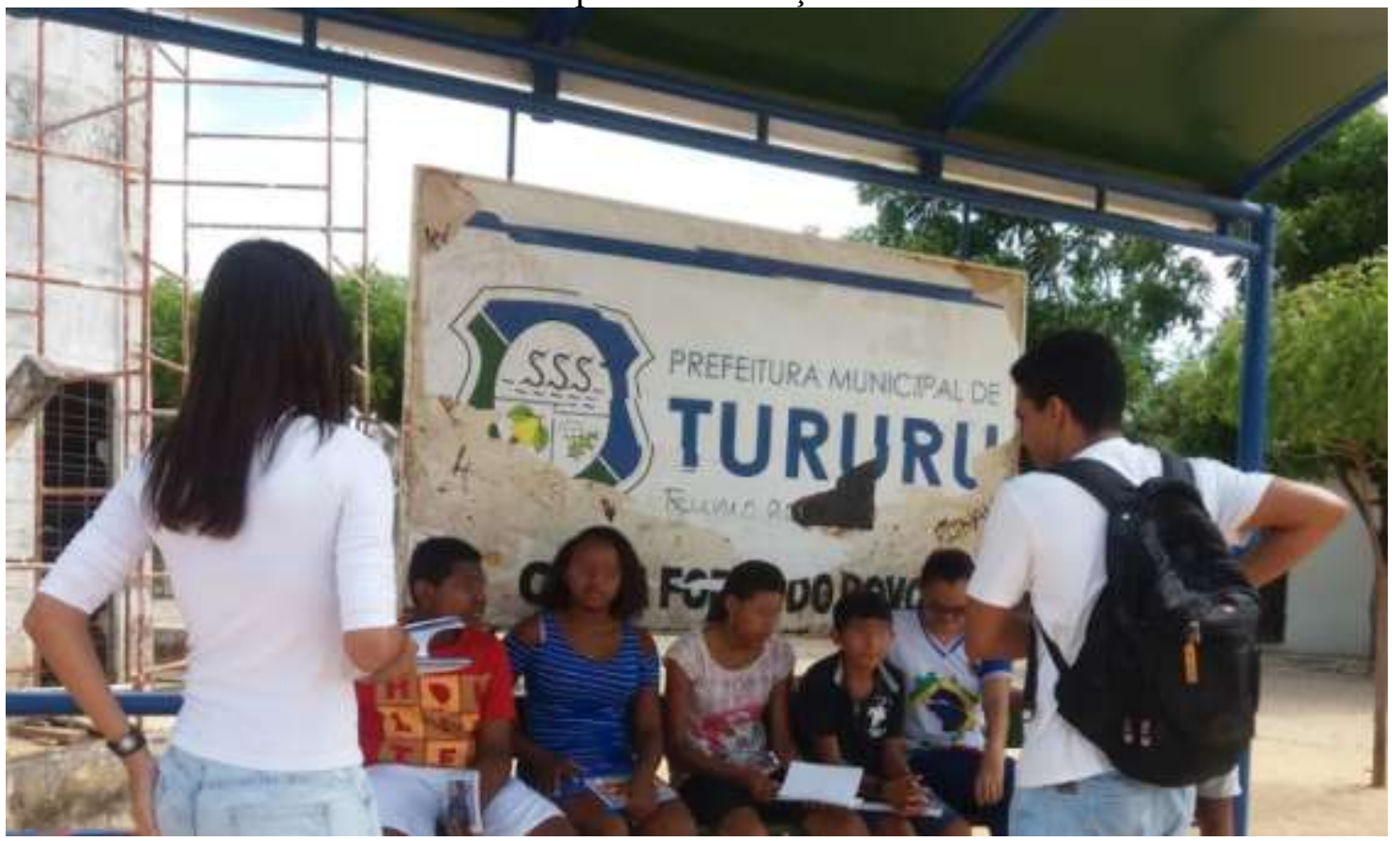

Fonte: Acervo do autor, 2020.

Falamos também sobre um posto de saúde recém-inaugurado para atender os moradores da Comunidade, enfatizando-o como evidência de desenvolvimento e da necessidade dos serviços públicos de qualidade para a Comunidade, que também se relaciona com o crescimento populacional e as reivindicações dos moradores.

Sobre o campo de futebol, que existe na comunidade, falamos sobre os torneios e jogos recreativos que sempre acontecem e como isso se torna um costume tradicional e corriqueiro. Outro costume local é a utilização recreativa do Rio Mundaú, que margeia a leste a Comunidade, que atrai fluxo de moradores locais e visitantes de outras localidades. 
Ao retornarmos à Escola, houve uma avaliação com os alunos destacando as contribuições e aspectos para melhorar a atividade das duas etapas realizadas. Após este momento, também houve também uma avaliação com o corpo pedagógico e gestor da Escola, com um apanhado das contribuições que as atividades proporcionaram e a constatação de que a atividade foi positiva.

Esta constatação se deu pelas considerações feitas pelos educandos, no sentido de exaltar que este tipo de prática abordando a Comunidade em que vivem foi uma experiência muito interessante, ao passo que gera novos olhares, novas perspectivas sob a ótica da Geografia a respeito do lugar em que habitam. E, de fato, a atividade representa uma possibilidade de trabalhar diversos conceitos geográficos - tais como o lugar, a paisagem, o território, a região, o desenvolvimento econômico, sociedade e natureza, cultura, dentre outros - lançando o olhar para a Comunidade e sendo viável a sua realização de maneira mais abrangente com relação aos alunos e com periodicidade anual.

\subsection{Mapeamento Colaborativo como ferramenta geoeducacional para as CRQs}

Após a realização das atividades em parceria com a EMEF Caetano José da Costa, emergiu a necessidade de uma aproximação maior com a Comunidade de uma maneira mais direta, indo além do âmbito escolar. Entendendo a Geografia não apenas enquanto ferramenta a ser apropriada nas escolas, mas também na comunidade em que se insere, desenvolvemos uma atividade que desse prosseguimento aos resultados obtidos com a prática anterior.

Seguindo as diretrizes do mapeamento participativo (GIRARDI, 2016), iniciamos os procedimentos com uma oficina de elementos da cartografia básica e dialogamos sobre elementos como: escalas, convenções cartográficas, orientação, polígonos, pontos e linhas, dentre outros elementos que compõem a estrutura básica de um mapa. Em seguida tratamos de possibilidades temáticas da cartografia, enfocando a questão patrimonial em sequência. Evitou-se o entendimento de conceitos fechados e prontos sobre patrimônio, buscando uma construção coletiva a partir do entendimento popular sobre o termo, destacando suas formas materiais e imateriais e a composição do que poderíamos em seguida chamar de patrimônio cultural de Conceição dos Caetanos.

Revista da ABPN • v. 12, n. Ed. Especial - Caderno Temático: “Geografias Negras” • abril de 2020, p. 153-174 
Ainda neste primeiro momento, identificamos, por meio de exemplos citados pelos moradores de Conceição dos Caetanos, alguns elementos imateriais e materiais que compõem seu patrimônio cultural. E a partir de imagens projetadas da Comunidade, geradas pelo software Google Earth - que visa apresentar um modelo tridimensional e navegável do globo terrestre, construído a partir de mosaico de imagens de satélite e mapeamento tridimensional - visualizamos os pontos marcantes da Comunidade. Fato destacável deste processo é que, a medida em que determinados locais eram identificados, algumas pessoas relataram histórias vividas e passadas de geração a geração, enquanto outras pessoas passaram a conhecer ou relembraram tais histórias. Tal socialização evidenciou ainda mais o caráter histórico de alguns lugares da Comunidade. Assim encerramos as atividades do primeiro dia.

Avançamos para uma explicação sobre o uso do overlay, que consiste em sobrepor uma camada de papel vegetal sobre um mapa base para a plotagem manual de elementos por parte da comunidade participante (Figura 3).

Figura 3: Mapeamento participativo com a técnica de overlay em Conceição dos Caetanos.

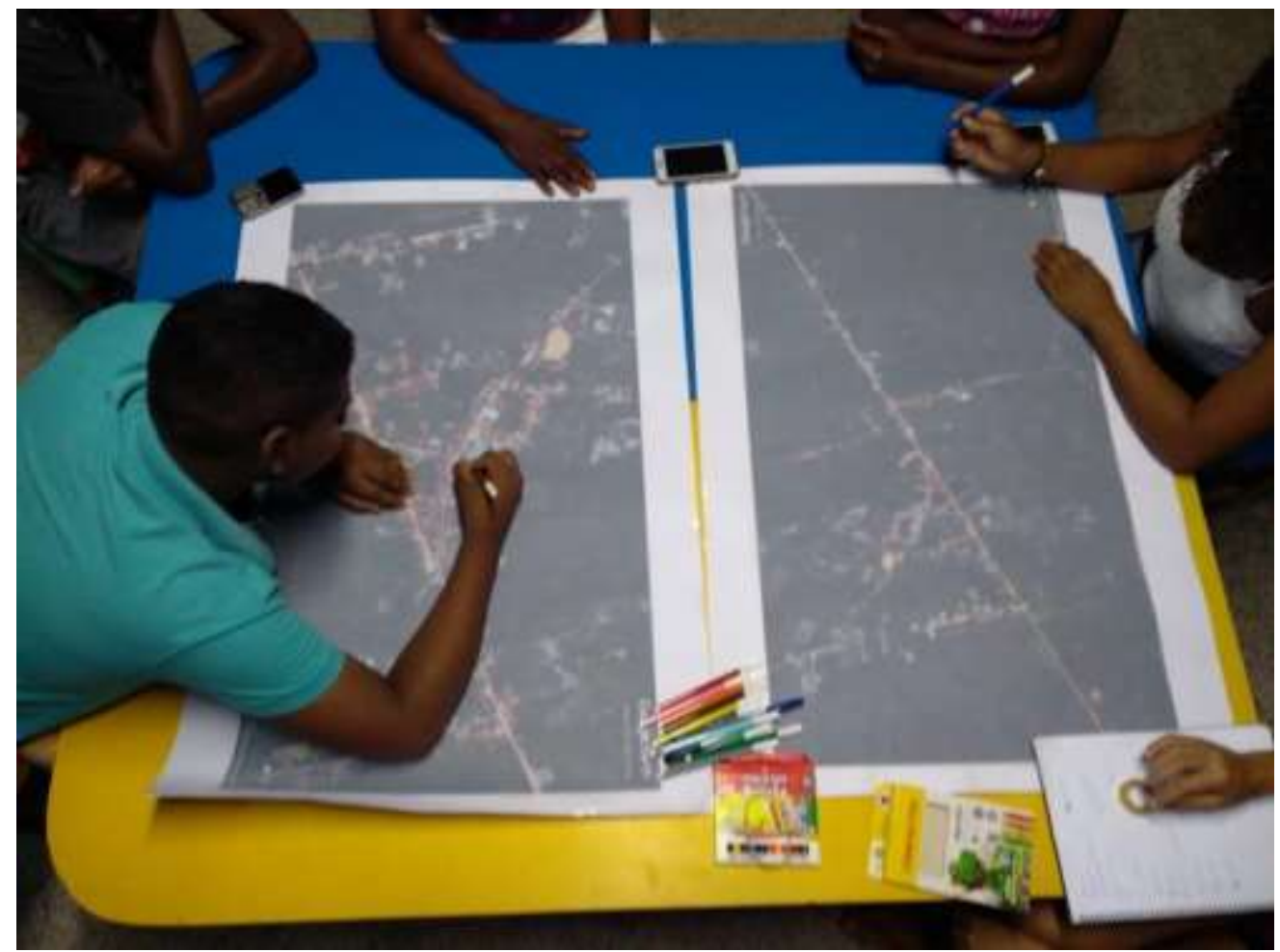

Fonte: Acervo do autor, 2020. 
Este processo permite a criação de mapas temáticos a partir do interesse da comunidade e das discussões elencadas no processo do mapeamento participativo. Após a elaboração do overlay, geramos um mapa com os elementos pontuados por meio de ambientes SIG (Sistema de Informação Geográfica). Por ser uma comunidade de grande área, mas também com uma centralidade que aglutina muitos locais representativos, os participantes utilizaram dois mapas para a produção do overlay, cada um com uma escala diferente. Da mesma forma, com vistas a melhorar a visualização dos ícones, produzimos um mapa com representação de diferentes escalas de análise.

Ao longo do processo, emergiu de maneira naturalizada uma divisão de elementos de forma temporal:

1) Espaços da Memória: locais que existiram no passado, mas ainda estão presentes no território quilombola por meio da preservação de sua memória.

2) Espaços Tangíveis: locais que tangíveis no presente dotados de importância especial para a Comunidade.

3) Espaços Projetivos: locais que de forma projetiva foram colocados no mapa como metas coletivas a serem alcançadas em prol de uma maior visibilidade ao patrimônio cultural da Comunidade.

Cada ponto mapeado recebeu um determinado desenho a ser representado na forma de ícone no produto final. A divisão dos ícones e suas divisões temporais pode ser vista no quadro seguinte (Figura 4). 
Figura 4: Elementos do patrimônio cultural de Conceição dos Caetanos.

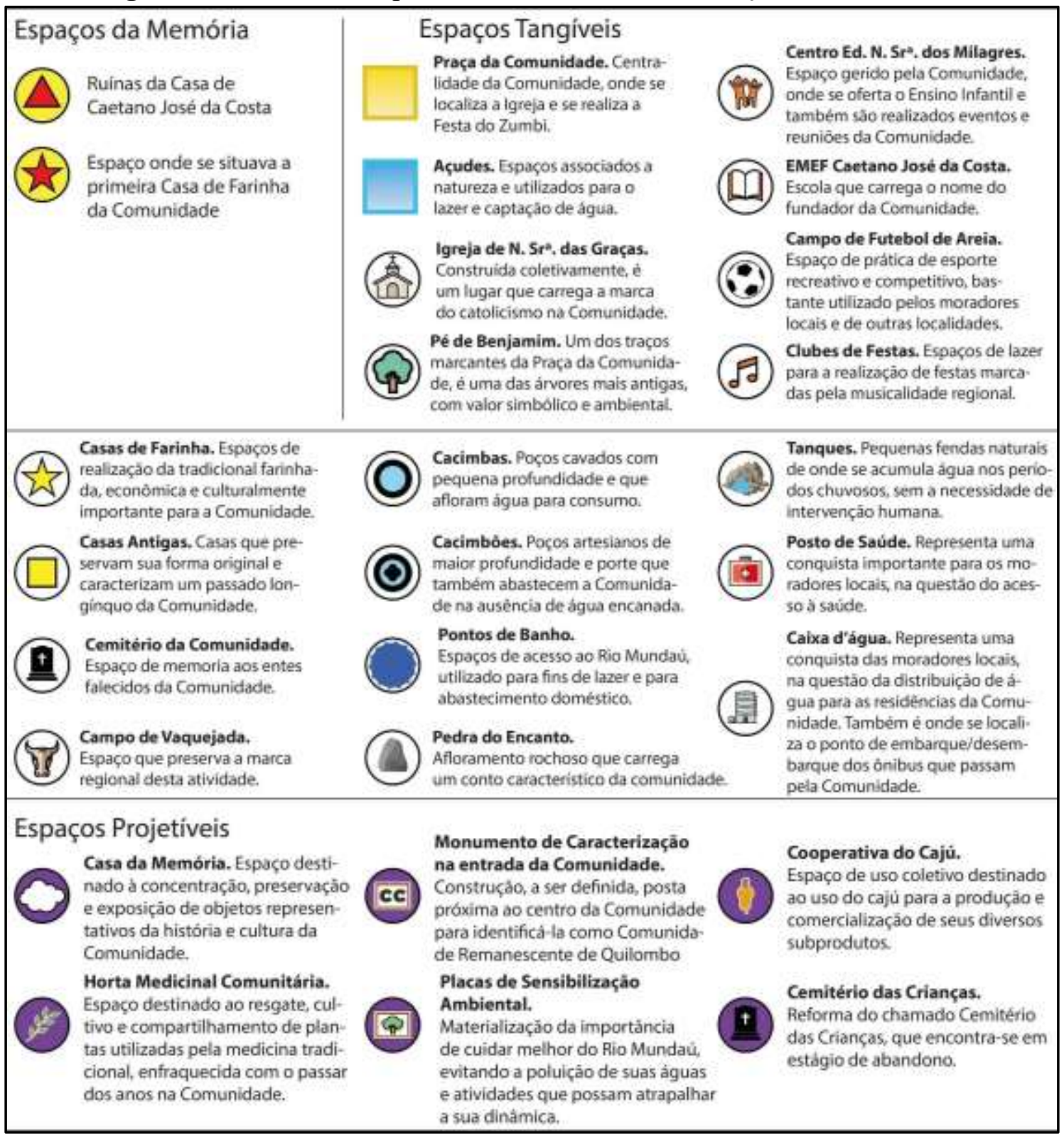

Fonte: Elaborado pelo autor, 2018.

Apesar da utilização de diferentes escalas cartográficas para a espacialização dos elementos patrimoniais, esta atividade representou um grande desafio de lidar com o detalhamento de uma quantidade considerável de elementos patrimoniais em uma escala cartográfica relativamente pequena.

O mapeamento participativo revelou a importância do Rio Mundaú, com quatro pontos de banho para a comunidade; além de outros pontos como casas de farinha, 
casas mais antigas da comunidade, elementos naturais também dotados de valor simbólico e locais de importância para a vida na comunidade.

Já a área central da comunidade destaca elementos como a praça central, a Igreja, a demarcação de onde ficava a primeira casa de farinha da comunidade, a Escola e o Centro Educacional da Comunidade (vistos como importantes espaços de preservação da cultura), dentre outros pontos presentes no Quadro 1.

Em ambos os recortes, é possível visualizar o que denominamos como espaços projetivos (Figura 4), que representam desejos de futuras construções com finalidades específicas. A plotagem destes elementos no mapa patrimonial revelou o interesse da Comunidade em se organizar em prol da valorização de sua história e sua cultura, a valorização e o enriquecimento de sua própria identidade. Ademais, esta prática expandiu a relação entre pesquisador e escola e alcançou uma relação entre pesquisador e comunidade, de maneira mais abrangente e envolvendo também alguns alunos da prática anterior.

Os elementos que compõem um quadro de referência cultural do que vem a ser o patrimônio quilombola para Conceição dos Caetanos, foram dispostos em um produto final mais completo, em formato de banner, que engloba o resultado cartográfico com um quadro que dispõe dos outros elementos imateriais não pontuados no mapa.

Todavia, um dos desafios presentes no processo de digitalização dos overlays se deu pelo levantamento, nas etapas anteriores, de elementos culturais imateriais que não puderam ser demarcados no mapa: as músicas criadas pela comunidade, ritualidades celebradas na Festa do Zumbi, alguns artesanatos criados pelas mulheres, a arte de fazer tranças própria da Comunidade, dentre outros elementos.

E para representar estes elementos imateriais, construímos um banner contendo o resultado cartográfico do mapeamento participativo e um quadro com os elementos imateriais que compõem o patrimônio quilombola da Comunidade. O referido material expandido pode ser apresentado em um stand educativo montado na Festa do Zumbi de 2018. Durante a noite festiva, foi feita a exposição do material e das folhas de overlay, socializando toda a construção do mapeamento e também o produto gerado pelo processo coletivo. No momento de exposição do banner elaborado, tanto para os moradores locais (participantes ou não do mapeamento participativo) quanto para os 
visitantes que prestigiaram a apresentação do material foi perceptível o reconhecimento da relevância do material construído para o contexto de Conceição dos Caetanos.

Ao longo do trabalho de construção, os participantes reconheceram a atividade do mapeamento como um processo importante para melhorar a articulação dos moradores no que tange a construção dos novos espaços e elementos para a Comunidade. No entendimento de algumas pessoas que prestigiaram o banner: "o mapa servirá para a Comunidade se organizar melhor em torno de suas demandas, principalmente as culturais"; "este trabalho tem uma grande importância para a Comunidade, porque esse tema precisa ser mais desenvolvido aqui"; e "este material (banner) que vai ficar na Comunidade vai ser de muita importância para a Escola, para trabalhar estes elementos patrimoniais com os alunos. Esse tipo de material ainda nunca tinha sido feito aqui e um trabalho dessa natureza é muito importante".

\section{CONSIDERAÇÕES FINAIS}

A reflexão em torno do conjunto de atividades desenvolvidas ao longo da pesquisa permite-nos considerá-las como possibilidades para o reconhecimento de um patrimônio geoeducacional quilombola para o ensino, primeiramente, nas próprias comunidades e, segundamente, no município como um todo. Compreender a dimensão do patrimônio quilombola na esfera do município é fundamental para o seu reconhecimento, visto que sua valorização não se garante apenas pelo reconhecimento interno, em cada comunidade, dos seus elementos patrimoniais, ou do reconhecimento das CRQs enquanto patrimônio cultural em si mesmas.

É preciso que a visibilidade deste patrimônio geoeducacional seja percebida no âmbito das escolas municipais como um todo, para que a valorização se torne efetiva na escala municipal. Neste sentido, compreende-se a necessidade de um diálogo maior do município de Tururu em torno das temáticas étnico-culturais com atividades realizadas em parceria com as CRQs do município.

$\mathrm{Na}$ condição de pesquisador-licenciando e descendente de moradores de Tururu, foi possível nesta rica experiência perceber diferentes aspectos interessantes que só se fizeram emergir por meio da interface entre uma experiência pessoal com o lugar, envolvendo a esfera particular do pertencimento, e um conjunto de leituras e 
aprendizagens construídas ao longo do curso de licenciatura em Geografia pela Universidade Federal do Ceará.

Ao longo de toda a construção da pesquisa, nenhum dos lados desta interface se ofuscou o outro. Pelo contrário, a experiência de pesquisar em um lugar já bastante conhecido qualificou ainda mais a percepção sobre o reconhecimento do patrimônio cultural e o papel do professor de Geografia neste percurso.

Por via dos conhecimentos acadêmicos, foi possível vislumbrar fenômenos presentes neste contexto que antes não poderiam ser devidamente percebidos, como a relevância dos aspectos patrimoniais culturais e das comunidades quilombolas, que compõem os sujeitos desta pesquisa; em contrapartida, o conjunto de experiências pessoais com o contexto geográfico pesquisado significou um arcabouço de conhecimentos que não seriam absorvidos completamente por meio científico.

Com base nesta reflexão, é possível reafirmar o papel do professor de Geografia, capaz de perceber nuances desta natureza. O professor neste contexto representa um importante agente de mobilização capaz de impulsionar algumas medidas necessárias em prol do autoreconhecimento patrimonial das CRQs. Pois o aperfeiçoamento de práticas geoeducativas e da articulação em diferentes escalas citadas é um caminho viável para a valorização do patrimônio quilombola de Tururu. Pois dessa forma, é possível desenvolver estratégias de valorização patrimonial para as comunidades e reivindicar a garantia de políticas públicas e o exercício de cidadania para estes grupos.

A educação geográfica possui importante papel na construção deste autoreconhecimento patrimonial. A partir das atividades de Educação Patrimonial e de Mapeamento Participativo, foi possível estabelecer diálogo entre os conhecimentos geográficos e diversos elementos histórico-culturais próprios das CRQs para trabalhar na concepção de um patrimônio geoeducacional quilombola.

Uma importante interface que dá sustentação para estas atividades se dá entre a escola e comunidade. É por meio deste vínculo que o papel do professor-pesquisador se faz fundamental no processo de construção de saberes contextualizados capazes de balizar conhecimentos teóricos e exemplos locais práticos por meio da temática cultural, tão importante para as escolas quilombolas. Exercícios como os que foram desenvolvidos neste trabalho demandam, ao mesmo tempo em que reforçam, os vínculos entre escola e comunidade. 
Compreende-se, porém, a necessidade de explorar diferentes projetos, práticas e programas de incentivo a valorização do patrimônio quilombola, sobretudo a partir da interação entre os conhecimentos geográficos (aperfeiçoados em práticas geoeducativas) e o contexto das comunidades tradicionais, que incorporam e constroem tais conhecimentos, que compõem uma perspectiva para se compreender sua territorialidade, sua geograficidade.

\section{AGRADECIMENTOS}

Ao Programa de Educação Tutorial (PET MEC/SESu) Geografia UFC e a Coordenação de Aperfeiçoamento de Pessoal de Nível Superior (CAPES), pelo apoio logístico e concessão de bolsa de estudos. Ao Laboratório de Estudos Geoeducacionais e Espaços Simbólicos (LEGES), pelo embasamento e sistemática de pesquisa em torno da temática proposta. E a Comunidade Quilombola de Conceição dos Caetanos, cuja parceria estabelecida foi crucial para o desenvolvimento do estudo, bem como desenvolvimento pessoal como pesquisador.

\section{REFERÊNCIAS BIBLIOGRÁFICAS}

ANJOS, Rafael Sanzio Araújo dos. Cartografia étnica: a África, o Brasil e os territórios dos quilombos.In: SILVA, J.B.; LIMA, L.C. e DANTAS, E.W.C. (orgs.) Panorama da geografia brasileira II. São Paulo: Annablume, 2006. p. 199-213.

BERUTTI, Flávio; LISBOA, Andrezza; SANTOS, Igor. Comunidades Quilombolas: espaços de resistência. Belo Horizonte: Rhj, 2012.

BRASIL. Lei $n^{\circ}$ 10693, de 9 de janeiro de 2003. Brasília, 9 jan. 2003. Disponível em: <goo.gl/xz4MJS>. Acesso em: 29 out. 2018.

. INSTITUTO BRASILEIRO DE GEOGRAFIA E ESTATÍSTICA. .Censo Demográfico. 2010. Disponível em: <goo.gl/XaqL2y>. Acesso em: 29 out. 2018.

INSTITUTO BRASILEIRO DE GEOGRAFIA E ESTATÍSTICA. 2018b. Tururu. Disponível em: <goo.gl/vX2bU6>. Acesso em: 28 out. 2018.

CALLAI, Helena. A formação do profissional da Geografia. Ijuí: Editora Unijuí, 2013.

CEARÁ. INSTITUTO DE PESQUISA E ESTRATÉGIA ECONÔMICA DO CEARÁ. .Ceará em Mapas. 2007. Disponível em: <goo.gl/FB9MNn>. Acesso em: 12 nov. 2018.

Revista da ABPN • v. 12, n. Ed. Especial - Caderno Temático: "Geografias Negras" • abril de 2020, p. 153-174 
CUNHA JUNIOR, Henrique Antunes. Quilombo: patrimônio histórico e cultural. Espaço Acadêmico, Maringá, v. 11, n. 129, p.158-167, fev. 2012.

FIGUEIREDO, Lauro César. Perspectivas de análise geográfica do patrimônio cultural: algumas reflexões. Geografia Ensino \& Pesquisa, Santa Maria, v. 17, n. 1, p.55-70, jan. 2013. Disponível em: <goo.gl/S61AEQ>. Acesso em: 27 jul. 2018.

FREIRE, Paulo. Ação cultural para a liberdade. São Paulo: Paz e Terra, 2001.

GIRARDI, Gisele. Mapeamento Participativo, Cartografia Social e Crítica: breves notas para um debate sobre práticas cartográficas escolares. In: AGUIAR, Lígia Maria Brochado de; SOUZA, Carla Juscélia de Oliveira. Conversações com a Cartografia Escolar: para quem e para que. São João del-Rei: UFJS, 2016. p. 83-96.

GORAYEB, Adryane; MEIRELES, Antonio Jeovah de Andrade; SILVA, Edson Vicente da (Org.). Cartografia social e cidadania: experiências de mapeamento participativo dos territórios de comunidades urbanas e tradicionais. Fortaleza: Expressão Gráfica, 2015.

HAESBAERT, Rogério. O mito da desterritorialização: do "fim dos territórios" à multiterritorialidade. 3.ed. Rio de Janeiro: Bertrand Brasil, 2007.

. Dos múltiplos Territórios à Multiterritorialidade. In: Heidrich, Álvaro et al. (Org.). A emergência da multiterritorialidade: a ressignificação da relação do humano com o espaço. $1^{\mathrm{a}}$ ed. Porto Alegre (RS): ULBRA e UFRGS, 2008. p. 19-36.

IPHAN. Educação Patrimonial: histórico, conceitos e processos. Brasília: Instituto do Patrimônio Histórico e Artístico Nacional, 2014.

OLIVEIRA, Christian Dennys Monteiro de. Caminhos da festa ao patrimônio geoeducacional: como educar sem encenar geografia? Fortaleza: Imprensa Universitária, 2014.

. Geoeducação das representações religiosas. In: Mercator, Fortaleza, v. 14, n.2, p.2143, mai. 2015. Disponível em: <goo.gl/RQRvmS>. Acesso em 08 nov. 2018.

OLIVEIRA, Christian Dennys Monteiro de; LIMA, Francisco John Lennon Alves Paixão; CARNEIRO, Icla Tamara Alves. Representações do patrimônio na Geografia escolar: o imaginário da festa religiosa cearense no ensino médio. In: Geografia Ensino \& Pesquisa. Santa Maria v. 17, n. 3, p. 127 - 42, set. 2013. Disponível em: <goo.gl/NPAhoo>. Acesso em: 27 nov. 2018.

PIMENTA, Selma Garrido e LIMA, Maria Socorro Lucena. Estágio e Docência. São Paulo: Cortez, 2004.

RATTS, Alecsandro José Prudêncio. Geografia, relações étnico-raciais e educação: a dimensão espacial das políticas afirmativas no ensino. In: Terra Livre. Ano 26, v. 1, n. 34. São Paulo, 2010.

SANTOMÉ, Jurjo Torres. As culturas negadas e silenciadas no currículo. In: SILVA. Tomaz Tadeu (org.). Alienígenas na sala de aula. Petrópolis, RJ: Vozes, 1995. p. 159-177.

SANTOS, Milton. A cidade nos países subdesenvolvidos. Rio de Janeiro: Ed. Civilização Brasileira S.A., 1965.

SILVA, Christian Nunes da; VERBICARO, Camila. O mapeamento participativo como metodologia de análise do território. Scientia Plena, Aracaju, v. 12, n. 6, p. 1-12, mai. 2018. Disponível em: <goo.gl/8oJecH>. Acesso em: 09 set. 2018. 
Recebido 20/02/2020

Aprovado em 30/03/2020 